\title{
Trace Amines and Mental Disorders
}

\author{
ALAN A. BOULTON
}

SUMMARY: In this brief review it will be possible to mention only superficially the bioclinical, behavioral, neurochemical, neuropharmacological and neurophysiological evidence to support the view that some of the trace amines [meta- and paratyramine (m-TA, p-TA), $\beta$-phenylethylamine $(P E)$ and tryptamine $(T)]$ may play a significant role in the propagation of

RESUME: Dans cette courte revue nous reverrons certains des arguments biocliniques, comportementaux, neurochimiques, neuropharmacologiques et neurophyologiques en faveur d'un rôle possible des micro-amines (meta et para-tyramine, nervous impulses and perhaps be involved in the etiology of certain mental disorders. More detailed comments will be found in some recent papers and reviews (Axelrodet al., 1976; Boulton, 1974, 1976, 1978, 1979; Boulton and Baker, 1975; Boulton and Juorio, 1979; Faurbye, 1968; Mosnaim and Wolfe, 1978; Sandler and Reynolds, 1976; Wyatt et al., 1977).

B-phenylethylamine et tryptamine) dans la popagation des influx nerveux et peut-être dans l'étiologie de certaines maladies mentales. D'autres revues plus complètes on récemment été publiées.

\section{Clinical}

It is well known that chronic amphetamine usage in man is capable of producing a state indistinguishable from paranoid schizophrenia (Connell, 1958). This drug is also used, paradoxically, as a treatment for hyperkinesis (Bradley, 1937). The trace amines mimic the amphetamine stereotypies in small mammals and have been claimed to be abnormally excreted in migraine, schizophrenia, depression, Parkinsonism, hypertensive crises, hyperkinesis, epilepsy, hepatic coma, phenylketonuria and hypertyrosinemia. In addition using appropriate trace amine substrates, abnormalities in platelet monoamine oxidase (MAO) and serum dopamine- $\beta$-hydroxylase $(\mathrm{D} \beta \mathrm{H})$ have been claimed to exist in schizophrenia and even in individuals psychiatrically 'at risk' (Coursey et al., 1979). In studies at the University Hospital in Saskatoon, whilst it has been possible to demonstrate abnormal urinary excretion levels of unconjugated $p$-TA, PE and T in 10-30\% patients admitted to the psychiatric ward, it has not yet proved possible to correlate, in any unambiguous way, these findings with any particular diagnosis or symptom. This situation also obtained when we undertook longitudinal studies in selected patients (Slingsby, 1975; Huebert, 1980).

\section{Neurochemical}

The TA's, PE and $T$ exist in the mammalian brain in tiny amounts $(<5 \mathrm{ng} / \mathrm{g}$ ) but are heterogeneously distributed both anatomically and subcellularly, being concentrated in the main in the basal ganglia. PE and T appear to arise as the result of decarboxylation of their parent amino acids and although this may also occur for the TA's, these particular trace amines also arise as a consequence of 
hydroxylation and dehydroxylation mechanisms. Because of this PE, $m$-TA, $p$-TA and $\mathrm{T}$ in addition to being structurally related are also metabolically interrelated with dopamine (DA), noradrenaline (NA), and 5-hydroxytryptamine (5-HT). The turnover rates of the trace amines are extremely fast being measured in minutes as opposed to hours. In slices of the caudate nucleus and hypothalamus $m$-TA and $p$-TA are concentrated by 'high' and 'low' affinity systems, which they may not necessarily share with dopamine and noradrenaline, since in the presence of certain drugs (desipramine and benztropine) $p$-TA, at least, has been shown to possess a unique uptake system of its own. Differences also exist between the TA's and DA and NA when these amines, previously accumulated, are released from slices in the presence of certain amines and drugs (Dyck et al., 1980).

\section{Neuropharmacological}

Differential effects are also seen with respect to the oxidative deamination of the trace amines in the presence of different monoamine oxidase inhibitors (MAOI). Depending upon the particular trace amine and MAOI, its concentration can be manipulated upward by as much as $10,000 \%$. PE is preferentially oxidised by MAO type B while $T$ and the TA's appear to respond to both type $A$ and type $B$. That the TA's may be stored, at least in part, is revealed by the decreases that follow treatment with reserpine and 6-hydroxydopamine (Boulton et al., 1977). The most intriguing property exhibited by $p$-TA in relation to $m$-TA and DA in the caudate nucleus and probably the mesolimbic system, however, is its reciprocal relationship in the presence of a wide range of stimulant drugs, neuroleptics, DA agonists and antagonists, DA precursors and synthesis blockers, as well as stress (Juorio, 1979, 1979a). Whether $p$-TA controls or modulates DA synthesis cannot at this time be determined.

\section{Neurophysiological}

When $m$-TA, $p$-TA and PE are iontophoresed onto cortical and caudate nucleus neurones, at currents similar to those used to elicit depressant effects with DA and NA (50 nA) similar depressant responses are obtained although they are weaker and shorter lasting (Henwood et al., 1979). When however the depressant effects of DA are measured during a continuous release of the trace amines with much weaker currents $(0-15 \mathrm{nA})$ a considerable potentiation of the DA effects (up to a nine-fold increase) are observed (Jones and Boulton, 1980 and Jones, personal communication). No potentiation was observed when GABA, glutamate or 5-HT were iontophoresed instead of dopamine. The excitatory responses to acetylcholine were somewhat reduced in about $30 \%$ of the cells studied. The extent of the potentiation of the depressant actions at least with respect to $p$-TA on DA, was dose related.

In the case of T and 5-HT on cortical neurones it was found that $T$ possessed potent depressant effects while 5-HT was divided with about $50 \%$ of the cells tested being depressed and the other $50 \%$ being excited (Jones, personal communication). It was again shown that a continuous weak background ejection of $\mathrm{T}(0-10 \mathrm{nA})$ considerably potentiated the depressant effects of 5HT. When $T$ was tested at low ejecting currents $(0-10 \mathrm{nA})$ on excitatory 5-HT neurones however we were surprised and intrigued to discover that the excitation was changed into a depressant response in almost all cases. These electrophysiological properties of the trace amines have been interpreted as supporting the concept advanced by Boulton $(1975,1976,1978,1979 a)$ that the trace amines act, either directly or indirectly as neuromodulators in catecholaminergic and serotoninergic mediated neurotransmission. It is also quite possible that in specific and discrete locations one or more of the trace amines may act directly as a neurotransmitter.

It is not difficult to imagine - if the trace amines behaved as neurohumors as defined by Dismukes (1979) and Boulton (1979a) - how an imbalance in their concentration in a particular location (i.e., a perturbation in their neuronal homeostasis) could lead to dysfunctions in processes subserving mentation and thus the behavioral manifestations that are seen in certain of the mental disorders.

\section{ACKNOWLEDGEMENTS}

I thank Saskatchewan Health and the MRC for continuing financial support.

\section{REFERENCES}

AXELROD, J., SAAVEDRA, J. and USDIN, E. (1978). In, Trace Amines and the Brain. (Eds. Usdin, E. and Sandler, M.) Marcel Dekker, Inc., New York, 1-20.

BOULTON, A.A. (1974). Amines and theories in psychiatry. Lancet, $2,7871$.

BOULTON, A.A. (1976). In, Trace Amines and the Brain. (Eds. Usdin, E. and Sandler, M.) Marcel Dekker, Inc., New York, 21-39.

BOULTON, A.A. (1978). The tyramines: Functionally significant biogenic amines or metabolic accidents? Life Sci., 23, 659-672.

BOULTON, A.A. (1979). Trace amines in the central nervous system. Int. Rev. Biochemistry, (Ed., K.F. Tipton) 26, 179-206.

BOULTON, A.A. (1979a). The trace amines: Neurohumours (cytosolic pre- and/or postsynaptic, secondary, indirect?) Behav. Brain Sci., 2, 418.

BOULTON, A.A. and BAKER, G. (1975). The subcellular distribution of $\beta$-phenylethylamine, $p$-tyramine and tryptamine in rat brain. J. Neurochem., 25, 477-481.

BOULTON, A.A. and JUORIO, A.V. (1979). The tyramines: Are they involved in the psychoses? Biol. Psychiat., 14, 413-419.

BOULTON, A.A. and JUORIO, A.V., PHILIPS, S.R. and WU, P.H. (1977). Effects of reserpine and 6-hydroxydopamine on the levels of some arylalkylamines in rat brain. Brit. J. Pharmac., 59, 209-214.

BRADLEY, C. (1937). The behavior of children receiving benzedrine. Am. J. Psychiat., 94, 577.

CONNELL, P.H. (1958). In, Amphetamine Psychosis. Chapman and Hall, London.

COURSEY, R.D., BUCHSBAUM, M.S. and MURPHY, D.L. (1979). Platelet MAO activity and evoked potentials in the identification of subjects biologically at risk for psychiatric disorders. Brit. J. Psychiat., 134, 372-381.

DISMUKES, K. (1979). New concepts of molecular communication among neurones. Behav. Brain Sci., 2, 409-448.

DYCK, L.E., BOULTON, A.A. and JONES, R.S.G. (1980). A comparison of the effects of methylphenidate and amphetamine on the simultaneous release of dopamine and $p$ tyramine or $m$-tyramine from rat striatal slices. Eur. J. Pharmacol. (in press)

FAURBYE, A. (1968). The role of amines in the aetiology of schizophrenia. Comp. Psychiat., 9, 155-177.

HENWOOD, R.W., BOULTON, A.A. and PHILLIS, J.W. (1979). Iontophoretic studies of some trace amines in the mammalian CNS. Brain Res., 164, 347-351.

HUEBERT, N. (1980). Metabolism and excretion 
of some trace amines in the rat and the human. Ph.D. thesis. University of Saskatchewan.

JONES, R.S.G. and BOULTON, A.A. (1980). Interactions between para-tyramine, metatyramine or $\beta$-phenylethylamine and dopamine on single neurones in the cortex and caudate nucleus of the rat. Can. J. Physiol. and Pharmacol., 58, 222-227.

JUORIO, A.V. (1979). Effect of stress and L-DOPA administration on mouse striatal tyramine and homovanillic acid levels. Brain Res., 179, 186-189.

JUORIO, A.V. (1979a). Drug-induced changes in the formation, storage and metabolism of tyramine in the mouse. Brit. J. Pharmac., 66, 377-384.

MOSNAIM, A.A. and WOLF, M.E. (1978). In, $\beta$-Phenylethylamine: A Metabolically and Pharmacologically Active Amine. Marcel Dekker, Inc., New York.

SANDLER, M. and REYNOLDS, G.P. (1976).
Does phenylethylamine cause schizophrenia? Lancet, 1, 70-71.

SLINGSBY, J.M. (1975). Factors affecting urinary excretion of arylalkylamines in a randomly selected psychiatric population. Ph.D. thesis, University of Saskatchewan.

WYATT, R.J., GILLIN, J.C. and STOFF D.M. (1977). In, Neuroregulators and Psychiatric Disorders. (Eds, Usdin, E.. Hamburg, D.A. and Barchas, J.A.) Oxford University Press, New York.

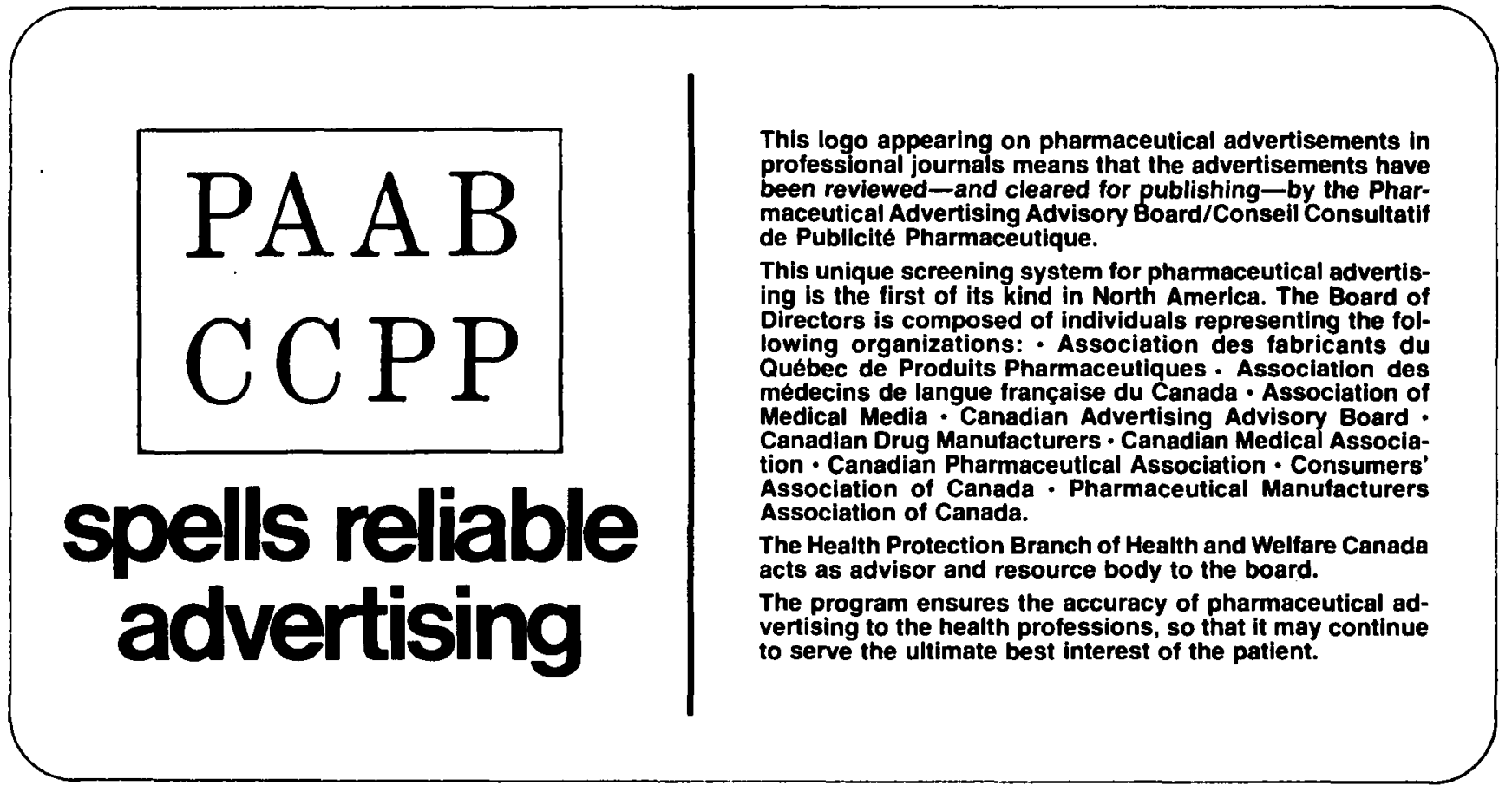

